\title{
Assessment of COPD-related outcomes via a national electronic medical record database
}

\author{
Carl Asche \\ Qayyim Said \\ Vijay Joish \\ Charles Oaxaca Hall \\ Diana Brixner \\ Pharmacotherapy Outcomes \\ Research Center, Department of \\ Pharmacotherapy, University of Utah \\ College of Pharmacy, Salt Lake City, \\ UT, USA
}

Purpose: The technology and sophistication of healthcare utilization databases have expanded over the last decade to include results of lab tests, vital signs, and other clinical information. This review provides an assessment of the methodological and analytical challenges of conducting chronic obstructive pulmonary disease (COPD) outcomes research in a national electronic medical records (EMR) dataset and its potential application towards the assessment of national health policy issues, as well as a description of the challenges or limitations.

Methods: An EMR database and its application to measuring outcomes for COPD are described. The ability to measure adherence to the COPD evidence-based practice guidelines, generated by the NIH and HEDIS quality indicators, in this database was examined. Case studies, before and after their publication, were used to assess the adherence to guidelines and gauge the conformity to quality indicators.

Results: EMR was the only source of information for pulmonary function tests, but low frequency in ordering by primary care was an issue. The EMR data can be used to explore impact of variation in healthcare provision on clinical outcomes. The EMR database permits access to specific lab data and biometric information.

Conclusions: The richness and depth of information on "real world" use of health services for large population-based analytical studies at relatively low cost render such databases an attractive resource for outcomes research. Various sources of information exist to perform outcomes research. It is important to understand the desired endpoints of such research and choose the appropriate database source.

Keywords: COPD, PFT, EMR, retrospective, dataset

\section{Background}

Healthcare utilization has expanded with the addition of electronically recording more clinical aspects of patients' charts including results of lab tests, vital signs, and other clinical information. The type of information contained within databases and the number of retrospective data sources has increased in just a few short years leading to the increased desire to utilize retrospective database analysis for several purposes including disease outcomes and end-points of therapy. Comparisons of outcomes have been made with observational studies against randomized, controlled trials in various disease states and have shown similar results (Benson and Hartz 2000; Concato et al 2000). Benson and Hartz (2000) hypothesized that the improvement in results of observational studies may be due to more sophisticated selection of datasets and statistical methods. Assessing disease states across different databases maximizes the strengths and minimizes the weaknesses of each individual database, which may be comparable to the effect of the multicenter aspect of a clinical trial. The objective of this study was to provide an assessment of the advantages and challenges of conducting chronic obstructive pulmonary disease (COPD) related outcomes research in a national EMR dataset and its potential application towards the assessment of national health policy issues. 


\section{Methods}

A national EMR database and its application to measuring outcomes for COPD are described. The ability of measuring adherence to the COPD evidence-based practice guidelines generated by the NIH and HEDIS quality indicators were examined using 2 case studies (GOLD 2005). A summary of the results and conclusions of these case studies are provided in Table 1.

\section{Data source}

The primary data source used for the case studies was the General Electric (GE) Centricity research database. Centricity EMR (Logician, Version 4.6, Hillsboro, Oregon, MedicaLogic/Medscape, Inc, 1994) is an EMR used by over 20,000 clinicians to manage 30 million patient records in 49 states. A subset of over 5,000 Centricity providers contributes data to the medical quality improvement consortium (MQIC) to create a research database. The MQIC represents a variety of practice types including solo practitioners, community clinics, academic medical centers, and large integrated delivery networks. Approximately two thirds of the participating clinicians practice primary care and others practice various specialties.

GE EMR data from 1996 to June of 2005 was available, and a subset of 1.1 million adult patients with indication of any metabolic condition, including type 2 diabetes, hypertension, or dyslipidemia, was utilized for this study. Patient data included demographic information, vital signs, laboratory orders and results, medication list entries, prescription orders, diagnoses, and problem lists.

\section{Case study \#I: Assessment of physician prescribing for primary care patients with COPD in a national EMR research database (Asche et al 2006)}

An EMR database of patients receiving care in primary care settings was queried to evaluate physician prescribing for COPD patients. This study was intended to provide limited access to pulmonary function test (PFT) data to assess physician prescribing for patients with COPD in accordance with Global Initiative for Chronic Obstructive Lung Disease Workshop report 1 guidelines (GOLD 2005). Patients with COPD (ICD-9 codes of 491.xx, 492.xx, 496) and available PFTs were identified and then stratified by GOLD severity classifications. Patients with a history of asthma were excluded. Physician prescribing of respiratory medications was evaluated from 180 days prior to 210 days post the most recent PFT (identified as the study period). Of 25,544 adult patients with COPD, less than 1\% (246) met the inclusion criteria of having both PFT and prescription data without a diagnosis of asthma prior to COPD, indicating either a lack of testing in primary care, a lack of documentation, or a limited transmission of PFT data into an EMR system. The use of maintenance bronchodilators among COPD patients in this study was low. Approximately $80 \%$ of COPD patients were prescribed "any bronchodilator" during the study period. When short-acting beta-agonists were not included, this proportion decreased to about $66 \%$. Inhaled corticosteroid (ICS) use appeared high among mild/moderate COPD patients and ranged from $39 \%$ in mild patients to $50 \%$ in very severe patients. Approximately $8 \%$ (severe) to $14 \%$ (mild, moderate, and very severe) of COPD patients were not prescribed any respiratory medications during the study period. Of the study population, $76 \%$ had moderate/severe COPD.

\section{Case study \#2: COPD early diagnosis and treatment initiation}

The General Electric Medical Quality Improvement Consortium (MQIC) database was queried for COPD patients. The expressed purpose of this study was to identify patterns of care related to initial diagnosis and/or treatment of COPD and explore time to initial treatment and diagnosis of COPD with the hopes of assisting earlier diagnosis and implementation of treatment. A total of 35,752 patients met the initial inclusion with COPD ICD-9 codes of 491.xx, 492.xx, 496.xx and at least 18 years of age at the time of diagnosis. Of these 14,691 had the 6 month history required for the analysis. Patients were stratified by disease severity level according to the GOLD report guidelines (Joish et al 2006). The dataset contained 1.75 million patients at the time of this query. It was found that the majority of patients (73\%) were diagnosed with a nonspecific ICD-9 code (496) for COPD, but no further classification was noted. Diagnosis of COPD is often made without PFT results and without any recorded history of risk factors. Only $4 \%$ of subjects that met the inclusion criteria had a recorded PFT, indicating that contrary to the GOLD treatment guidelines it is not routinely used to diagnose, classify, or guide treatment of COPD. Of those that did have a PFT recorded and available at the time of diagnosis, they had COPD Class 2 or higher. Analysis of prescribing patterns confirmed that COPD is not diagnosed or treated until the later stages of the disease. Depending on the class of medication prescribed, the mean time between the physician order and the time of diagnosis ranged from 389-781 days. Similar results were seen for time of symptom related to COPD to time of diagnosis of COPD. A reason for this delay in diagnosis and treatment may be that many patients were initially misdiagnosed for 
Table I Results and conclusions from each analysis

\begin{tabular}{|c|c|c|c|c|c|}
\hline Case & Title & Study purpose & $\begin{array}{l}\text { Data \& patient } \\
\text { population }\end{array}$ & Results & Conclusions \\
\hline I & $\begin{array}{l}\text { Assessment of physician } \\
\text { prescribing for primary } \\
\text { care patients with } \\
\text { COPD in a National } \\
\text { EMR Research Database }\end{array}$ & $\begin{array}{l}\text { The assessment of } \\
\text { physician prescribing } \\
\text { using a national EMR } \\
\text { research database for } \\
\text { patients with COPD vs. } \\
\text { GOLD guidelines with } \\
\text { limited availability of } \\
\text { PFT data to determine } \\
\text { disease severity. } \\
\text { This study was intended } \\
\text { to assess prescribing vs. } \\
\text { guidelines. }\end{array}$ & $\begin{array}{l}\text { GE } \\
\text { - A national EMR } \\
\text { research database of } \\
\text { patients receiving care } \\
\text { in primary care settings } \\
\text { was queried. } \\
\text { - Patients with COPD } \\
\text { were stratified by } \\
\text { GOLD severity } \\
\text { classifications. } \\
\text { - Patients with a history } \\
\text { of asthma were } \\
\text { excluded. } \\
\text { - Physician prescribing } \\
\text { of respiratory } \\
\text { medications was } \\
\text { evaluated the most } \\
\text { recent PFT for the } \\
\text { study period. } \\
\text { - Initial data cut = 25,544 }\end{array}$ & $\begin{array}{l}\text { Only } 246 \text { had both PFT } \\
\text { and prescription data } \\
\text { without a diagnosis of } \\
\text { asthma prior to COPD. } \\
\text { - Of the study population, } \\
76 \% \text { had moderate/ } \\
\text { severe COPD. } \\
\text { - Approximately } 80 \% \\
\text { of COPD patients } \\
\text { were prescribed a } \\
\text { bronchodilator.When } \\
\text { SAB were not included, } \\
\text { this proportion } \\
\text { decreased to about } 66 \% \text {. } \\
\text { ICS use ranged from } 39 \% \\
\text { in mild patients to } 50 \% \text { in } \\
\text { very severe patients. } \\
\text { Approximately } 8 \%-14 \% \\
\text { (all severity levels) of } \\
\text { COPD patients were } \\
\text { not prescribed any } \\
\text { respiratory medications. }\end{array}$ & $\begin{array}{l}\text { - }<1 \% \text { of COPD } \\
\text { patients in the database } \\
\text { had PFT data, indicating } \\
\text { either a lack of testing, } \\
\text { documentation, or } \\
\text { limited transmission of } \\
\text { PFT data into the EMR } \\
\text { system. } \\
\text { - The use of } \\
\text { maintenance broncho- } \\
\text { dilators among COPD } \\
\text { patients was low. } \\
\text { ICS use appeared high } \\
\text { among mild/moderate } \\
\text { COPD patients. }\end{array}$ \\
\hline 2 & $\begin{array}{l}\text { COPD early diagnosis } \\
\text { and treatment initiation }\end{array}$ & $\begin{array}{l}\text { Identify patterns of } \\
\text { care related to COPD } \\
\text { exploring time to } \\
\text { initial treatment and } \\
\text { diagnosis of COPD } \\
\text { stratified by disease } \\
\text { severity level according } \\
\text { to the GOLD report } \\
\text { for COPD to facilitate } \\
\text { earlier diagnosis and } \\
\text { implementation of } \\
\text { treatment }\end{array}$ & $\begin{array}{l}\text { GE } \\
\text { - The GE centricity data- } \\
\text { base contained I.75 } \\
\text { million patients at the } \\
\text { time of this query. } \\
\text { - } 14,691 \text { had the } \\
6 \text { month history } \\
\text { required. } \\
\text { - Initial data cut = 35,752 } \\
\text { with the COPD ICD-9 } \\
\text { codes. }\end{array}$ & $\begin{array}{l}\text { Only } 4 \% \text { of COPD } \\
\text { patients had any } \\
\text { recorded PFT and were } \\
\text { a Class } 2 \text { or higher } \\
\text { according to GOLD } \\
\text { guidelines. } \\
\text { - } 73 \% \text { of patients had an } \\
\text { ICD-9 code for general } \\
\text { COPD, but were not } \\
\text { further classified. } \\
\text { The mean time between } \\
\text { the physician order and } \\
\text { the time of diagnosis } \\
\text { ranged from } 389-78 \text { I } \\
\text { days. Similar results were } \\
\text { seen when symptoms } \\
\text { were analyzed. } \\
\text { Many patients were } \\
\text { initially misdiagnosed for } \\
\text { asthma (32\%) or acute } \\
\text { bronchitis (28\%). }\end{array}$ & $\begin{array}{l}\text { COPD is not diagnosed } \\
\text { or treated until later } \\
\text { classes. } \\
\text { - PFTs are not routinely } \\
\text { used to diagnose, } \\
\text { classify or guide } \\
\text { treatment of COPD. } \\
\text { Diagnosis of COPD is } \\
\text { often made without } \\
\text { PFT results and } \\
\text { without any recorded } \\
\text { risk factors. }\end{array}$ \\
\hline
\end{tabular}

Abbreviations: SAB, short-acting bronchodilators; PFTs, pulmonary function tests; COPD, chronic obstructive pulmonary disease; EMR, electronic medical records; ICS, inhaled corticosteroid.

asthma $(32 \%)$ or acute bronchitis $(28 \%)$ before then being diagnosed for COPD.

\section{Discussion}

In this article, two cases or analyses are presented using the same database. The data contained has inherent qualities making research both challenging and advantageous (Table 2).
Both case studies utilized the MQIC database. The advantage of this database was the total amount of specific information regarding each patient. It contained demographic information, vital signs, laboratory orders and results, clinical outcomes, payment plans, type of payment, prescription and OTC medications, and medication lists. However, possibly due to recording failure, spirometry data was scarce. 
Table 2 Advantages and limitations of the national EMR database

\begin{tabular}{|c|c|c|c|}
\hline Case & Database & Advantages & Challenges \\
\hline$I$ and 2 & $\begin{array}{l}\text { GE } \\
\text { The General Electric MQIC database }\end{array}$ & $\begin{array}{l}\text { - Large database which included: } \\
\text { demographic information, } \\
\text { vital signs, spirometry data (to } \\
\text { determine disease severity), labs, } \\
\text { outcomes, payment plans, type } \\
\text { of payment, and medications } \\
\text { including OTC. }\end{array}$ & $\begin{array}{l}\text { - Less than I\% of COPD patients in } \\
\text { the database had spirometry data. } \\
\text { - For the most part, the EMR only } \\
\text { captures primary care physician } \\
\text { prescribing. Cannot distinguish } \\
\text { primary care physicians and } \\
\text { specialists. } \\
\text { - Prescription data was analyzed } \\
\text { and de-identified and due to this } \\
62 \% \text { of the patients had one or } \\
\text { more medication lines blocked. } \\
\text { Oxygen use was captured } \\
\text { through medical diagnosis rather } \\
\text { prescription orders. }\end{array}$ \\
\hline
\end{tabular}

Abbreviations: MQIC, General Electric Medical Quality Improvement Consortium.

Also, apparently oxygen use was more often captured through medical claims rather than prescription claims. This indicated that researchers may need to truly look for the data they are searching for in unexpected places. Another challenge was that one could not distinguish care provided by primary care provider (PCP) versus specialist. The final challenge of this database, after de-identification of patient data for HIPAA requirements, is that researchers are left with a large portion of text derived data blocked and unattainable due to potential identifying language.

\section{Conclusions}

Healthcare information collected in the database described within this report are generally being collected for alternative reasons than patient outcome research. Despite various methods used to make data consistent, there are inherent deficiencies that impact the quality of this data for research purposes. Researchers must consider the research questions and desired endpoints when choosing a data source to minimize the limitations. Ultimately the contribution of well designed studies across various databases, in combination with information from randomized clinical trials, can provide important information towards health care management and policy decisions.

\section{References}

Asche CV, Young D, Brixner DI, et al. Assessment of physician prescribing for primary care patients with chronic obstructive pulmonary disease (COPD) in a national electronic medical record (EMR) research database. Poster presentation at the 72nd Annual International Assembly of the American College of Chest Physicians (ACCP). Chest, October 21-26, 2006. Salt Lake City, Utah.

Benson K, Hartz AJ. 2000. A comparison of observational studies and randomized, controlled trials. $N$ Engl J Med, 342:1878-92.

Concato J, Shah N, Horwitz RI. 2000. Randomized, controlled trials, observational studies, and the hierarchy of research designs. $N$ Engl $J$ Med, 342:1887-92.

[GOLD] Global Initiative for Chronic Obstructive Pulmonary Disease. 2005. Global Strategy for the diagnosis, management, and prevention of chronic obstructive pulmonary disease. NHLBI/WHO workshop report, 2001 (updated 2005) [online]. Accessed November 10, 2007. URL: http://www.goldcopd.com.

Joish VN, Brady E, Stockdale W, et al. 2006. Evaluating diagnosis and treatment patterns of COPD in primary care. Treat Respir Med, 5:283-93. 